\title{
EDITORIAL
}

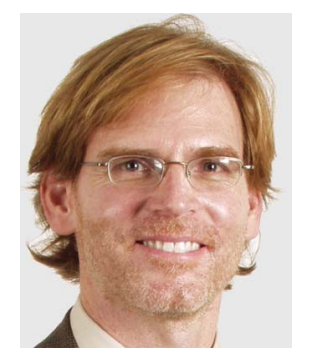

\section{Looking Back, Looking Ahead}

It is hard to believe that it has been 10 years since SPIE asked me to become the editor-in-chief of the Journal of Biomedical Optics (JBO), following in the footsteps of Joe Lakowicz, the founding editor-in-chief. My initial surprise and disbelief gradually transformed into acceptance and enthusiasm as I was assured by the SPIE staff that they would do whatever was necessary to produce the kind of journal that I envisioned. Today, I am grateful to Joe, SPIE, the editorial board, and our community for giving me an opportunity to help build a journal that meets the special needs of our field.

A decade ago we were a relatively small quarterly, publishing about 50 papers per year. Remarkably, in 2008, 328 peerreviewed papers appeared in JBO and we are now receiving an average of more than one manuscript every day (nearly 450 in 2008). JBO has helped define our field with 35 special sections on high-impact topics, ranging from biophotonics in women's health to small animal imaging, fluorescent proteins, cardiovascular photonics, and coherent Raman imaging (see $\mathrm{http}: / /$ spie.org/jbo for a list of previous and upcoming special sections). Many of these have been "firsts" for the scientific community.

In addition to special technical areas, JBO has established two major recurring "signature" issues: (1) Pioneers in Biomedical Optics and (2) Optical Methods from Bench to Bedside. In the former category, four of our field's visionary leaders and mentors-Britton Chance, Watt Webb, A. J. Welch, and Franz Jobsis - have been recognized, and a fifth, Tayyaba Hasan, will be honored in 2010. Three "Bench to Bedside" special sections have appeared and a fourth is upcoming, all of which follow from the National Institutes of Health "Bench to Bedside" workshop on optical technologies that Amir Gandjbakhche and colleagues organize every few years. This extraordinary workshop highlights the unique role optical technologies can play in powerful, cost-effective solutions to important medical problems facing society.

Ten years ago it was rare for a journal published by a physics/engineering society to be indexed in Index Medicus/ Medline. One of my early responsibilities as editor-in-chief was to submit a formal application, based on the journal's accomplishments and future direction, to the National Library of Medicine (NLM) for indexing JBO in the world's most important biomedical database. Although this may not seem impressive by today's Google standard, NLM approval of our request in 2000 was an important step forward in the growth of the journal. This was followed in 2001 by our first impact factor, which has averaged 3.246 over the past six years.

Of course, helping fuel JBO impact is the increased availability of manuscripts. We have introduced the tremendously successful open-access "JBO Letters" section of the journal, and overall JBO downloads have grown from $\sim 16,000 / \mathrm{yr}$ in 2003 to $\sim 82,000 / y r$ in 2008 . In order to accommodate this growth, JBO publication frequency has increased from quarterly to bimonthly, to what is now essentially continuous, with accepted manuscripts appearing online immediately after professional copyediting, typesetting, and proofing. And our authors can now do this with several options: multimedia files, color online, and several open-access choices (see http:// spie.org/jbo for a description of options).

None of this could have happened without the extraordinary support and talent of SPIE's highly professional staff, a brilliant editorial board, and our prolific community. JBO operates on a daily basis because of the efforts of a few outstanding, dedicated people, managing editor Karolyn Labes, peer review coordinator Rita Davis, and editorial assistant Debbi Gordon. Additional help is provided by the clever artists and staff who develop the journal covers and assemble each issue, including graphic artist Jill Mathews and senior editor Rebecca Saxton. All of this is managed by Eric Pepper, SPIE's judicious director of publications. I am grateful to all for their tireless efforts, thoughtful guidance, and, perhaps most important, their patience with me over the past 10 years.

I am equally grateful to my colleagues on the editorial board and our special section editors for supporting the journal and volunteering so much of their time. Your dedication to the JBO vision has enriched our field and has had a substantial impact on the broader scientific community. Finally, I am always amazed and inspired by our authors, reviewers, and readers. These contributions are essential and irreplaceable, and I hope you will continue to be involved just as passionately over the next decade. Having an opportunity to see the most exciting, state-of-the-art biomedical research come "across the transom" has been a remarkable privilege. As editor-in-chief, I am thrilled to have been in the middle of this and appreciative of the opportunity to help stimulate and facilitate new discoveries and even help resolve occasional disputes.

Ten years is a complete term for editors-in-chief of SPIE journals, and this editorial signifies that I have successfully 
"graduated" to the next stage. Although I haven't yet determined what to do with all of my new "free" time, I am thrilled that my extraordinarily talented colleague, Lihong Wang of Washington University in St. Louis, will be taking over as editor-in-chief of the journal. Under his guidance, I am confident JBO will continue to grow and expand in scope and impact. JBO has thrived, in part, because it offers our community a recognized avenue for original expression that is not available in any other journal. Importantly, we have led the charge in high-profile growth areas, such as bench to bedside translational research and in vivo molecular imaging. The natural mix of creativity, technical innovation, and practical biomedical problem solving that appears in every issue is precisely what makes JBO unique. I urge everyone to continue to support our journal as our field is poised to expand its special role in the generation of new knowledge and technologies that directly benefit society.
Bruce J. Tromberg Editor-in-Chie 